\title{
Microstructural characterization of friction welded TiAl-Ti6Al4V hybrid joints
}

\author{
V. Ventzke ${ }^{1, a}$, H.-G. Brokmeier ${ }^{2,1, b}$, P. Merhof ${ }^{3, c}$ and M. Koçak ${ }^{1, d}$ \\ ${ }^{1}$ GKSS-Forschungszentrum Geesthacht $\mathrm{GmbH}$, \\ Institut für Werkstoffforschung, Geschäftsbereich Werkstoffmechanik, \\ Max-Planck-Straße 1, D-21502 Geesthacht, Germany \\ ${ }^{2}$ Technische Universität Clausthal, Fakultät für Natur- und Materialwissenschaft, \\ Institut für Werkstoffkunde und Werkstofftechnik, \\ Agricolastraße 6, D-38678 Clausthal-Zellerfeld, Germany \\ ${ }^{3}$ GEA Tuchenhagen GmbH, Berliner Straße 25, D-21514 Büchen, Germany \\ avolker.ventzke@gkss.de, bbrokmeier@gkss.de, 'cmerhof.peter@tuchenhagen.de, 'musta- \\ fa.kocak@gkss.de
}

Keywords: $\gamma$-TiAl, Ti6Al4V, dissimilar friction welding, microhardness, microstructure, microtexture

\begin{abstract}
This paper describes microstructure and microtexture development in dissimilar friction welded $\gamma$-TAB-Ti64 joints. The effect of friction welding parameters on microstructure and local properties are examined and discussed. It was found that the intermetallic $\gamma$-TiAl based alloy Ti47Al-3.5( $\mathrm{Mn}+\mathrm{Cr}+\mathrm{Nb})-0.8(\mathrm{~B}+\mathrm{Si})$ (denoted as $\gamma-\mathrm{TAB})$ is more sensitive to the applied friction welding parameters used in this study. Furthermore, the bonding between these two alloys was controlled by a diffusion process during a very short process duration. Grain refinement as well microstructure transformation led to local improvement of the friction-welded joints.
\end{abstract}

\section{Introduction}

Multi-material systems are becoming attractive for complex lightweight constructions with respect to functionality, cost and weight reduction. The unique advantages of $\gamma$-TiAl based alloys may be dissimilarly combined with materials exhibiting higher fracture toughness and ductility, and thus balancing disadvantages such as high brittleness and pronounced notch sensitivity of $\gamma$-TiAl. This approach may be useful for damage tolerance applications. Duan et al. [1] and Çam et al. [2] have investigated the bondability of dissimilar $\gamma$-TiAl-Ti6242 and $\gamma$-TiAl-Ti6Al4V joints using TLP and diffusion bonding. Çam et al. [2] have considered the case of an exhaust valve produced by final joining of the cap section from intermetallic $\gamma$-TiAl alloy made via investment casting to a stem section made from a more ductile commercial Ti6Al4V alloy. Axial friction welding is an alternative to diffusion bonding as shown on similar friction welded $\gamma$-TiAl and Ti6Al4V [3]. The alloy Ti47 $\mathrm{Al}-3.5(\mathrm{Mn}+\mathrm{Cr}+\mathrm{Nb})-0.8(\mathrm{~B}+\mathrm{Si})$ in investment cast condition was successfully friction welded without any defects in the bonding zone with a very short process duration of 60-70 s compared to diffusion bonding which requires much longer process period [3]. Furthermore, properties of this welded alloy are essentially found to be affected by the properties of its as-cast base material and not by the weld interface [4]. However, one should note that the cylindrical sample geometry required may constitute a limitation. In the present study interfacial microstructure of the dissimilar friction welds with particular emphasis on local properties as microhardness, microtexture and chemical composition is reported. 


\section{Experimental Procedure}

Materials: The materials in this study were Ti-47Al-3.5( $\mathrm{Mn}+\mathrm{Cr}+\mathrm{Nb})-0.8(\mathrm{~B}+\mathrm{Si})$ in investment cast and hot isostatic pressed condition and wrought Ti6Al4V (denoted as $\gamma$-TAB and Ti64 in this study). The microstructure of $\gamma$-TAB was fully lamellar morphology and contains alloying elements Al, Cr, Mn, Nb, Si and B [5]. The Ti64 alloy used in this study was delivered in wrought, annealed and descaled condition and shows globular microstructure. The commercial Ti64 consists the hexagonal $\alpha$ phase stabilized by Al and the body-centered $\beta$ phase stabilized by V. The effect of alloying elements and microstructures in Ti based alloys are comprehensive described by Boyer et al. [6]. Table 1 gives the chemical composition and tensile properties of the $\gamma$-TAB as well as Ti64 alloy.

Table 1: Chemical composition and tensile strength of investment casted $\gamma$-TAB [5] and wrought Ti6Al4V.

\begin{tabular}{|c|c|c|c|c|}
\hline Alloy & $\mathbf{A l}$ & $\mathrm{Mn}+\mathrm{Cr}+\mathrm{Nb}$ & $\mathbf{B}+\mathbf{S i}$ & $\mathbf{T i}$ \\
\hline$\gamma$-TAB & 47 & 3.5 & 0.8 & Balance \\
\hline $\mathrm{R}_{\mathrm{p} 0.2}$ & \multicolumn{4}{|c|}{$500 \mathrm{MPa}$ at $\mathrm{RT}\left(410 \mathrm{MPa}\right.$ at $\left.700^{\circ} \mathrm{C}\right)$} \\
\hline $\mathrm{R}_{\mathrm{m}}$ & \multicolumn{4}{|c|}{$550 \mathrm{MPa}$ at $\mathrm{RT}\left(500 \mathrm{MPa}\right.$ at $\left.700^{\circ} \mathrm{C}\right)$} \\
\hline A & \multicolumn{4}{|c|}{$\leq 4 \%$} \\
\hline Alloy & Al & $\mathbf{V}$ & $\mathbf{F e}$ & $\mathbf{T i}$ \\
\hline Ti6Al4V & 6.21 & 4.07 & 0.18 & Balance \\
\hline $\mathrm{R}_{\mathrm{p} 0.2}$ & \multicolumn{4}{|c|}{$940 \mathrm{MPa}$} \\
\hline $\mathrm{R}_{\mathrm{m}}$ & \multicolumn{4}{|c|}{$1003 \mathrm{MPa}$} \\
\hline A & \multicolumn{4}{|c|}{$10-15 \%$} \\
\hline
\end{tabular}

Friction welding: Specimens with relatively large diameters were friction welded on near-industrial conditions using the friction path as an essential parameter. The advantage of this parameter is the reproducibility of the friction abridgement. All welded specimens had a diameter of $25 \mathrm{~mm}$. The $\gamma$ $\mathrm{TAB}$ alloy was received in form of an investment cast block. Cylindrical specimens of $25 \mathrm{~mm}$ in diameter and $50 \mathrm{~mm}$ in length were cut from this block by spark erosion machining technique. The contacting surface of the $\gamma$-TAB specimens was milled in order to reduce the roughness and remove remnants from the spark erosion machining procedure. The Ti64 alloy was provided in form of a bar. Cylindrical specimens of $25 \mathrm{~mm}$ in diameter and $100 \mathrm{~mm}$ in length were cut and the contacting surface of the Ti6A14V specimens was milled. The specimen lengths were different because of material saving. It is to be mentioned that the contacting surfaces were not polished by buffing. All friction welds were produced using a continuous drive friction-welding machine. The entire friction welding process passed through 4 phases: abrasion, friction, braking of the rotation and upsetting. Thus, the specimens were subjected to compressive stresses during the friction and upsetting phase as well as by warm torsion stresses during the braking phase. At the end of the stop time, the friction pressure was increased to higher values of upsetting pressure. The process parameters, such as friction pressure $\mathrm{P}_{\mathrm{F}}$, friction path $\mathrm{s}_{\mathrm{F}}$, upsetting pressure $\mathrm{P}_{\mathrm{U}}$ and upsetting time $\mathrm{t}_{\mathrm{U}}$, were systematically varied in order to determine an optimal process route as well as to obtain sound dissimilar joints between these two alloys. The average process time $t_{\mathrm{Pr}}$ of $4.7 \mathrm{~s}$ as well as average shortening $\mathrm{S}_{\mathrm{E}}$ of $7.2 \mathrm{~s}$ resulted from the friction pressure, friction path, upsetting pressure and upsetting time as shown in Table 2. 
Table 2: Friction welding parameters and conditions used. The rotational speed was held constant at $1470 \mathrm{rpm}$. The abrade time was $1 \mathrm{~s}$. The pressure values given in bar were converted into MPa.

\begin{tabular}{|c|c|c|c|c|c|c|}
\hline Specimens & $\mathbf{P}_{\mathbf{F}}[\mathbf{M P a}]$ & $\mathbf{S}_{\mathbf{F}}[\mathbf{m m}]$ & $\mathbf{P}_{\mathbf{U}}[\mathbf{M P a}]$ & $\mathbf{t}_{\mathbf{U}}[\mathbf{s}]$ & $\mathbf{t}_{\mathbf{P r}}[\mathbf{s}]$ & $\mathbf{S}_{\mathbf{E}}[\mathbf{m m}]$ \\
\hline \#08-TABTi64 & 310 & 6.00 & 330 & 1.80 & 4.6 & 7.08 \\
\hline \#09-TABTi64 & 310 & 6.00 & 340 & 1.80 & 4.7 & 7.18 \\
\hline \#10-TABTi64 & 310 & 6.00 & 360 & 1.80 & 4.6 & 7.38 \\
\hline
\end{tabular}

Microstructural investigations: The microstructure of dissimilar friction welded $\gamma$-TAB-Ti64 joints was investigated by scanning electron microscopy (Jeol JSM-6490LV) using EDX (EDAX Genesis) to examine local chemical gradients at the interface between these two alloys and electron backscatter diffraction (EDAX TSL OIM) to determine local textures. Microhardness profile across and parallel to the bonding zone was obtained using an automated Vickers hardness testing machine at $0.5 \mathrm{~kg}$ load. Metallographic specimen for back-scatter imaging and EDX analysis as well as EBSD were prepared by conventional procedures followed by a final polish with a oxide polish suspension (OPS) compound. Care was taken during grinding and polishing to protect the surface region against deformation and contamination. The EBSD measurements were performed in the thermomechanically affected zones as well as the base materials covering an area of $180 \mu \mathrm{m} \times 180 \mu \mathrm{m}$, at $25 \mathrm{kV}, 0.3 \mathrm{nA}$ of spot size, emission current of $60 \mu \mathrm{A}$, magnification of 500x, working distance of $15 \mathrm{~mm}$, step size of $5 \mu \mathrm{m}$ and sample tilt of $70^{\circ}$. The orientation calculation was conducted based on the GSHE method, whereas a triclinic sample symmetry was assumed, because sample axis and welding direction were not exactly parallel to another. EDX analyses were performed at of $20 \mathrm{kV}$ and lower working distance of $10 \mathrm{~mm}$. The data obtained were calculated based on the ZAF method.

\section{Results and Discussion}

\section{1 $\gamma$-TAB-Ti64-joints}

Figure 1a shows dissimilar friction welded $\gamma$-TAB-Ti64 joints. It is clearly visible that the flash is developed on the Ti64 side only. Furthermore, one-sided contraction occurred in the Ti64 region. The surface on the $\gamma$-TAB side was strongly oxidized adjacent to the interface. The presence of these oxide layers is an indication of a high process temperature, generated during friction welding. It is well known that process temperature is mainly dependent on the friction pressure when rotation speed is constant. The relationship between these two values is linear [7]. A macrograph of cross section of bonding between $\gamma$-TAB and Ti64 is shown in Figure 1b. The width of thermomechanically affected zone (TMAZ) decreases from the outer region towards the rotation centre. Hence, the TMAZ exhibits an axial symmetrical wedge shape. Cracks are formed on the $\gamma$-TAB side. Moreover, the $\gamma$-TAB alloy was not thermo-mechanically affected at rotation centre adjacent to the bond-line. The wedge shape of the TMAZ and the adjacent unaffected $\gamma$-TAB area at the rotation centre indicate that the friction heat was not evenly distributed over the entire interface. Furthermore, the shear stress was higher in the outer region than in the inner region. This means that the axial and the radial plastic deformation in the outer region was correspondingly higher. Bohm et al. [3] have shown that shear stress is linearly dependent on the radius and friction pressure, whereas the friction coefficient is expediently viewed as constant value. Hence, in this context it can be assumed that the temperature field is a function having a causal radius dependence also, because plastic deformation may deliver an additional contribution to the heat due to the interior friction. 


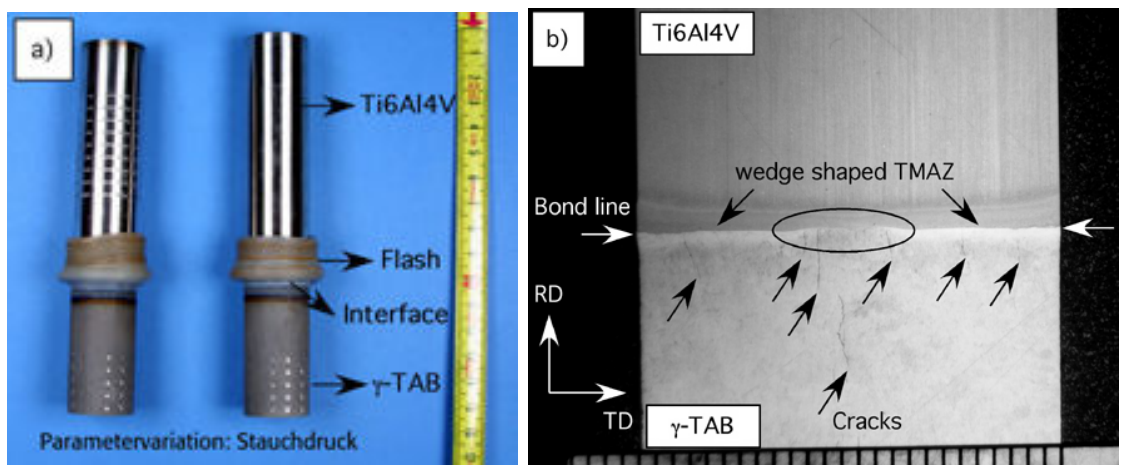

Fig. 1: a) As-friction welded TiAl-Ti6Al4V hybrid joints; b) Macrograph of bonded $\gamma$-TAB and Ti6Al4V in cross section. The wedge shaped TMAZ is clearly noticeable. The $\gamma$-TAB alloy was not affected at the rotation centre adjacent to the bond line (marked by circle).

\subsection{Hardness profile}

Hardness profiles were determined parallel to the bond line (TD) as well as across the bond (RD) as schematically shown in Figure $2 \mathrm{a}$. Figures $2 \mathrm{~b}$ and $2 \mathrm{c}$ illustrate the hardness profiles of the dissimilar joints produced with the parameters as shown in Table 2 . As seen from Figure $2 \mathrm{a}$ the radial microhardness of the Ti64 alloy within the TMAZ is almost constant. This means that there is no gradient in radial direction. The average value of the microhardness is $370 \mathrm{HV} 0.5$. The microhardness of Ti64 base material is slightly lower having an average microhardness of $330 \mathrm{HV} 0.5$, respectively. The radial microhardness of the $\gamma$-TAB alloy within the TMAZ was nearly constant in the range from 0 to $8 \mathrm{~mm}$ and then dropped to a minimum at the rotation centre. The average microhardness is $530 \mathrm{HV} 0.5$ in the outer region and $330 \mathrm{HV} 0.5$ in the inner region. The range of minimum microhardness corresponds to the width of the unaffected area of the $\gamma$-TAB alloy adjacent to the bond line as shown in Figure 1b. At the position of $15 \mathrm{~mm}$ the radial microhardness is increasing up to the maximum of $530 \mathrm{HV} 0.5$. The average microhardness of the $\gamma$-TAB base material is $250 \mathrm{HV0.5}$. The difference between base material and unaffected area at the rotation centre on the $\gamma$-TAB side is due to strain hardening. The axial hardness profile shown in Figure $2 \mathrm{c}$ exhibits a slight increase of microhardness from the base material to the TMAZ on the Ti64 side, whereas the $\gamma$-TAB side shows an extremely steep rise of microhardness. The response of the $\gamma$-TAB alloy to the applied friction welding parameters is essentially more pronounced than that of the Ti64 alloy.
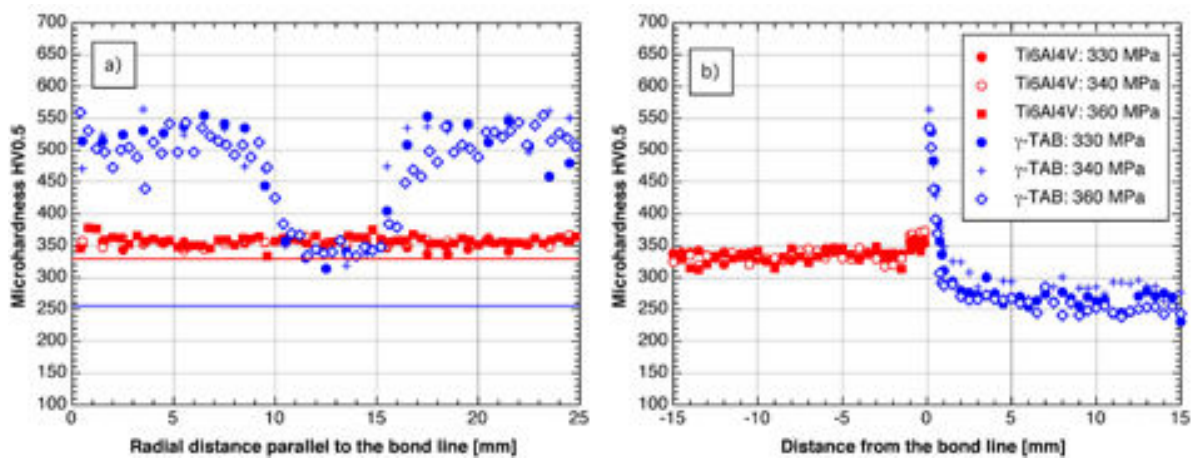

Fig. 2: The radial hardness profiles were determined within the TMAZ. The axial hardness profile captures the base materials as well as the TMAZ; a) Microhardness measurements parallel to the bond line; b) Microhardness measurements across the bonds.

\subsection{Microstructure and Microtexture}

Grains within the Ti64 base material were equiaxed, their average size was about $4.0 \mu \mathrm{m}$ (Fig. 3a). Phase analysis using EBSD yielded that the Ti64 base material contains $91.5 \% \alpha$ phase and $8.5 \%$ 
$\beta$ phase, respectively. The equiaxed microstructure resulted from mechanical working the Ti64 alloy in the $(\alpha+\beta)$-phase field and subsequent annealing. The pronounced Ti64-sided flash development as well as plastic deformation during friction welding is due to superplastic conditions given by the small grain size of $4.0 \mu \mathrm{m}$ and high process temperatures. The TMAZ exhibited lamellar microstructure on the Ti64 side containing $88.2 \% \alpha$ phase and $11.8 \% \beta$ phase, respectively (Fig. $3 b$ ). The average grain size was about $2.8 \mu \mathrm{m}$. In contrast to the base material, the TMAZ has a higher volume fraction of $\beta$ phase due to friction welding at a process temperature higher than $\beta$ transus. At this temperature the volume fraction of $\beta$ phase is very high. Orhan et al. [8] has reported that the amount of $\beta$ is increasing with increasing temperature. The authors gave the $\beta$ transus to be at $995^{\circ} \mathrm{C}$ in the case of the Ti64 alloy. The cooling from $\beta$ into $(\alpha+\beta)$-phase field has led to the local transformation of equiaxial initial structure into a lamellar structure in the Ti64 alloy. The corresponding basal plane pole figure of the Ti64 base material is shown in Figure 3a. The basal planes appear nearly perpendicular to the normal direction (ND), but slightly tilted at an angle of about $\alpha \approx$ $14^{\circ}$ into the welding direction (RD) and $\beta \approx 10^{\circ}$ around the ND of the base material. The texture of Ti64 base material is near to $\{0001\}<11-20>$. In the TMAZ, the basal planes are partially tilted into the welding direction $\left(\alpha \approx 90^{\circ}\right)$ and rotated around the ND $\left(\beta \approx 13^{\circ}\right)$ of the TMAZ (Fig. 3b). This means that basal planes of the $\alpha$ phase in the TMAZ are nearly parallel to the bond line and its orientation is near to $\{11-20\}<0001>$. Moreover, the (0002)-pole figure as shown in Figure $3 b$ exhibits two further orientations in close vicinity to the normal direction. Their polar angles are $\alpha \approx$ $32^{\circ}$ and $\beta \approx 45^{\circ}$ and $\alpha \approx 24^{\circ}$ and $\beta \approx 295^{\circ}$, respectively.
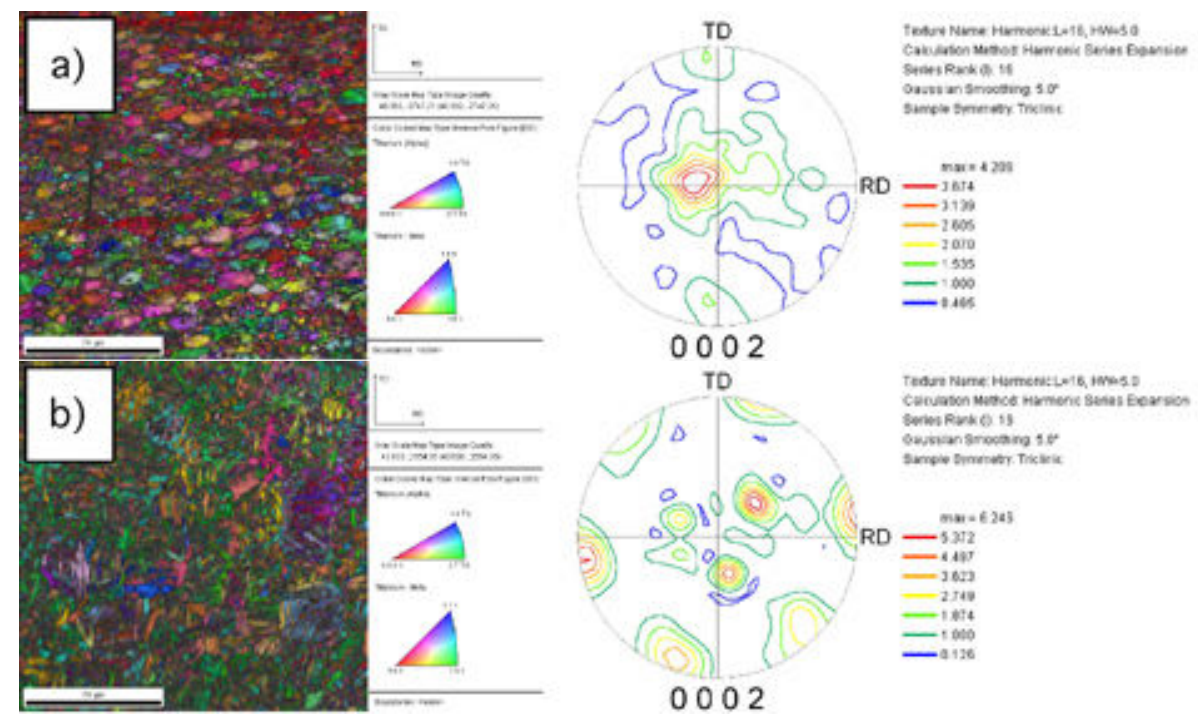

Fig. 3: EBSD orientation maps and corresponding pole figures. a) Ti64 base material $\left(\mathrm{P}_{\max }=4.209 \mathrm{mrd}\right)$; b) Ti64 TMAZ $\left(\mathrm{P}_{\max }=6.246 \mathrm{mrd}\right)$.

The base material of the $\gamma$-TAB in investment cast condition reveals a coarse-grained fully lamellar microstructure consisting of $\gamma$ and $\alpha_{2}$ phases having $57.7 \% \gamma$ phase and $42.3 \% \alpha_{2}$ phase, respectively. The average lamellae width was about $7.1 \mu \mathrm{m}$ (Fig $4 \mathrm{a}$ ). The orientation map shows a boundary between two lamellae colonies. It was not possible to examine the average grain size due to its coarse microstructure. Figure $4 \mathrm{~b}$ shows the fine-grained TMAZ (A) microstructure near interface to the bondline located between the rotation centre and the outer region. It was found that the average grain size was about $12.0 \mu \mathrm{m}$. Phase analysis using EBSD has yielded that the TMAZ (A) contains $61.6 \% \alpha_{2}$ phase and $38.4 \% \gamma$ phase. The fine-grained TMAZ (B) microstructure within the outer region containing $50.2 \% \alpha_{2}$ phase and $49.8 \% \gamma$ phase has an average grain size about $6.1 \mu \mathrm{m}$ (Fig. 4c). Probably the process temperatures reached during the friction welding were above $\alpha$ transus, because the TMAZ on the $\gamma$-TAB side is composed of a fine-grained lamellar microstructure. The coarse as-cast microstructure of the $\gamma$-TAB alloy was locally broken up due to compressive 
stresses during the friction and the upsetting phase as well as by warm torsion stresses during the braking phase. The local refinement resulted from the dynamic recrystallization during joining and cooling from $\alpha$ via $(\alpha+\gamma)$ into $\left(\alpha_{2}+\gamma\right)$-phase field. These different grain sizes explain the observed drop of microhardness in the radial direction within the TMAZ on the $\gamma$-TAB side as shown in Figure $2 \mathrm{~b}$. This means that the local microhardness is primarily determined by the grain size and not by the $\gamma / \alpha_{2}$-phase distribution, i.e. the Hall-Petch mechanism is active. The corresponding (111) pole figure of the $\gamma$-TAB base material is shown in Figure $4 \mathrm{a}$. A part of $\{111\}$ slip planes appear almost perpendicular to transversal direction. They are tilted at an angle of about $\alpha \approx 90^{\circ}$ and rotated around the ND at an angle of about $\beta \approx 78^{\circ}$. Another part of $\{111\}$ slip planes are tilted at an angle of about $\alpha \approx 16^{\circ}$ and rotated around the ND at an angle of about $\beta \approx 232^{\circ}$. However, it is to be mentioned that the pole figure is not representative because of the poor grain statistics as well as coarsegrained microstructure. Brokmeier et al. [9] reported that the $\gamma$-TAB base material used in this study is characterized by a $<111>$ fiber texture. The microtexture within $\gamma$-TAB-sided TMAZ is characterized by an inhomogeneity. In the TMAZ (A), the $\{111\}$ slip planes are nearly perpendicular to the welding direction (RD) (Fig. 4b). They are tilted at an angle of about $\alpha \approx 90^{\circ}$ into welding direction and rotated around the normal direction (ND) at an angle of about $\beta \approx 5^{\circ}$. In the TMAZ (B), the $\{111\}$ slip planes are nearly perpendicular to the normal direction (ND) (Fig. 4c). They are slightly tilted at an angle of about $\alpha \approx 16^{\circ}$ into welding direction (RD) and rotated around the normal direction (ND) at an angle of about $\beta \approx 33^{\circ}$. The multiple of the random density is decreasing from base material via TMAZ (A) to TMAZ (B).
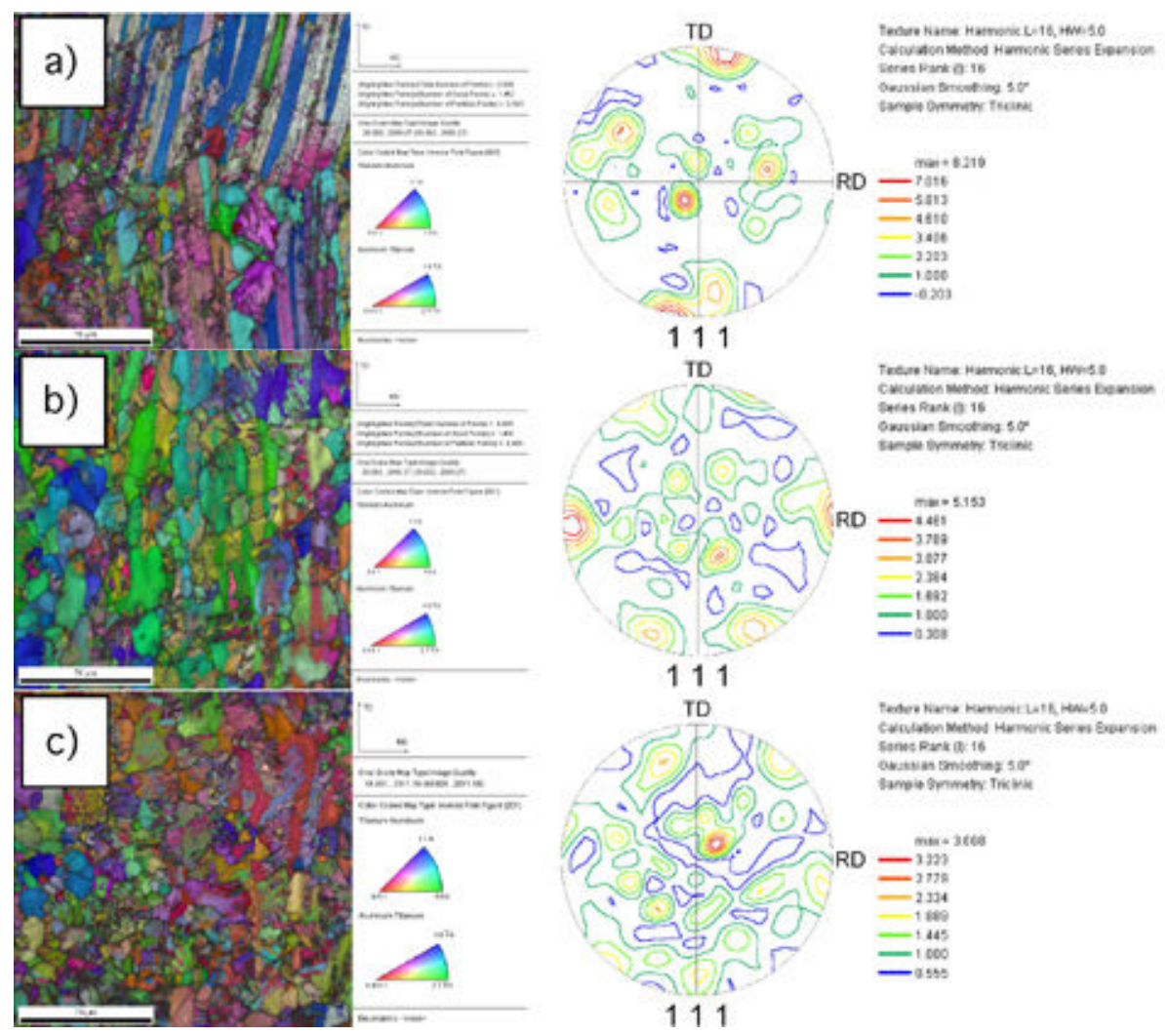

Fig. 4: EBSD orientation maps and corresponding pole figures. a) $\gamma$-TAB base material $\left(\mathrm{P}_{\max }=8.219 \mathrm{mrd}\right)$; b) TMAZ (A) between the outer range and rotation centre $\left(\mathrm{P}_{\max }=5.153 \mathrm{mrd}\right)$; c) TMAZ (B) within the outer region $\left(\mathrm{P}_{\max }=3.668\right.$ mrd)

The friction welding has led to a local optimization of dissimilar $\gamma$-TAB-Ti64 joint, because $\gamma$-TABsided grain refinement of the fully lamellar microstructure improves the creep behaviour, ductility and strength as well as lamellar Ti64 alloy is characterized by a high fracture toughness and possess superior resistance to creep and fatigue crack propagation $[6,10]$. 
However, a large number of voids were formed at the interface and were uniformly aligned along the bond line (Fig. 5b). It can be assumed that elastic and plastic deformation to achieve a planatation of bonding surfaces during friction welding was not sufficient resulting in voids as surface roughness remnants. Moreover, a reaction zone was detected located on the Ti64 side near interface to the bondline (Fig. 5b). The width of the reaction zone on the Ti64 side within in the inner region is smaller than in the outer region (Fig. 5c). The $\gamma$-TAB side near the interface to the bond line exhibits coarse-grained fully lamellar microstructure consisting of $\gamma$ and $\alpha_{2}$ phases, not differing from the microstructural properties of the base material. From this it follows that the local temperature was lower than the $\alpha$ transus and higher than the $\beta$ transus due to presence of lamellar microstructure on the Ti64 side adjacent to the bond line.
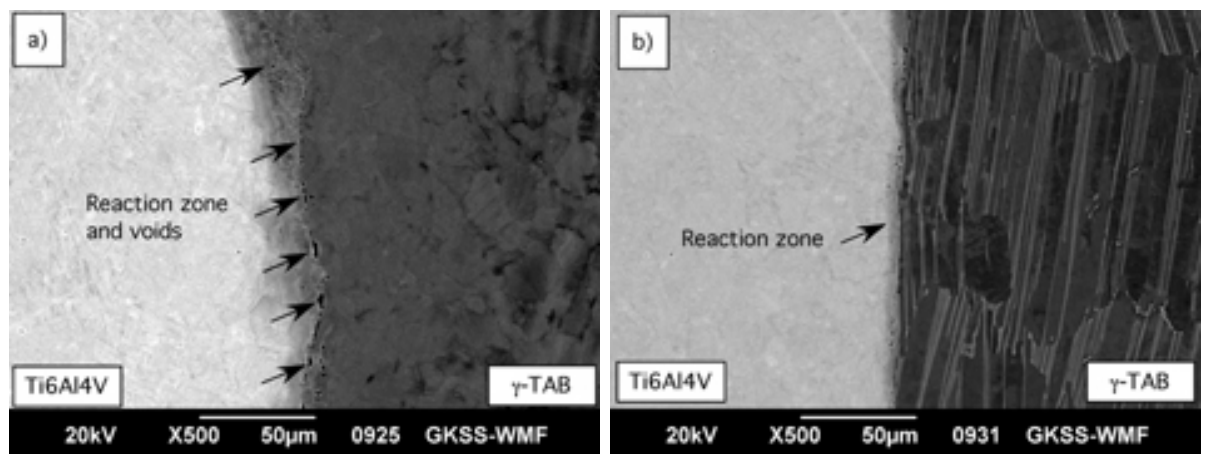

Fig. 5: Back-scattered micrographs showing the bond line; a) Ti64-sided reaction zone and large numbers of voids at the interface within the outer region, b) microstructure within the inner region at the rotation centre.

The detailed EDX point analyses in this reaction zone indicated that this newly formed phase is probably $\alpha_{2}$ phase having a chemical composition of $61-69$ at.- $\%$ Ti and $28-36$ at.- $\%$ Al. The chemical composition profiles were also obtained using EDX analysis across the bond line to determine the bonding mechanism (Fig. 6a and 6b). The profiles show that there is transport of $\mathrm{Al}$ and $\mathrm{Nb}$ atoms from the $\gamma$-TAB side toward to Ti64 side and of Ti and $\mathrm{V}$ atoms in the opposite direction. The $\mathrm{Al}$ and Ti contents are nearly constant within a small $\alpha_{2}$ region adjacent to $\gamma$-TAB side. From this it follows that a diffusion process controlled the bonding between these two alloys. It is remarkable that diffusion occurred during the short process duration of $5 \mathrm{~s}$ (Table. 2).
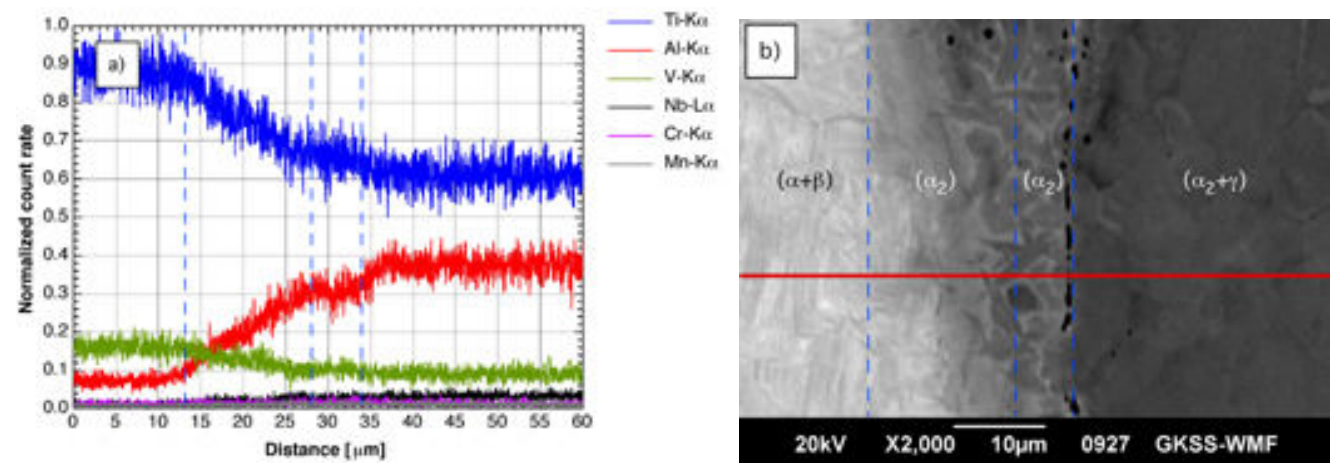

Fig. 6: a) EDX profiles for $\mathrm{Ti}, \mathrm{Al}, \mathrm{V}, \mathrm{Nb}, \mathrm{Cr}$ and $\mathrm{Mn}$ obtained across the bond line; b) the micrograph showing corresponding position where line analysis was conducted within the outer region. 


\section{Conclusions}

The friction welding parameters as used in this study have led to a local increase of isotropy degree due to both the $\gamma$-TAB-sided local grain refinement and the locally different microstructural orientations of the $\{111\}$ slip planes. Furthermore, the friction welding resulted in the local transformation of equiaxed initial microstructure into a lamellar microstructure in the Ti64 alloy. These obtained local microstructural changes may-be deliver a contribution to the damage tolerance of dissimilar $\gamma$ TAB-Ti64 joints. The bonding mechanism was controlled by the diffusion process and has led to the formation of $\alpha_{2}$ phase on the Ti64 side near interface to the bond line. The local microhardness is primarily determined by the grain size and not by the $\gamma / \alpha_{2}$-phase distribution, i.e. the Hall-Petch mechanism was active. Local texture development, width of reaction zone as well as the microstructural changes were controlled by radius dependence of temperature field as well as shear stress during friction welding. However, the friction welding parameters used in this study were not sufficient to achieve defect-free dissimilar $\gamma$-TAB-Ti64 joints. The joints exhibited cracks on the $\gamma$-TAB side and large number of voids at the interface of the joints. There is a need for further optimization.

\section{References}

[1] H. Duan et al.: Science and Technology of Welding and Joining Vol. 9 (2004), No. 6, p. 525.

[2] G. Çam et al.: Journal of Materials Science Vol. 43 (2008), p. 3491.

[3] K.-H. Bohm et al.: Welding and Cutting Vol. 55 (2003), No.2, p. 90.

[4] V. Ventzke et al.: Materialwissenschaft und Werkstofftechnik Vol. 37 No.8 (2006), p. 649.

[5] R. Wagner et al.: Proceedings Intern. Symp. on $\gamma$-Titanium Aluminides (ISGTA 95), Las Vegas. (ed. Y.-W. Kim, R. Wagner, M. Yamaguchi), TMS Warrendale (1995), p. 387.

[6] R. Boyer, G. Welsch and E.W. Collings (Ed.): ASM International, Metals Park, OH (1998), p. 483-636.

[7] O. T. Midling and, Ø. Grong: Acta metall. mater. Vol. 42 No. 5 (1994), p. 1595.

[8] N. Orhan et al.: Scripta Materialia Vol. 45 (2001), p. 441.

[9] H.-G. Brokmeier et al.: Z. Kristallogr. Supl. Vol. 26 (2007), p. 305-310.

[10] J. Kumpfert: Titanaluminide - Eine neue Legierungsklasse für Hochtemperaturanwendungen. In: Titan und Titanlegierungen. DGM Informationsgesellschaft, Oberursel 1999, p. 71-106. 